\title{
Sympathy, comparative markedness, OT-CC and Latin syncope
}

\author{
HAIKE JACOBS
}

Abstract

This paper focuses on opaque Latin vowel deletion and its relevance to the actual theoretical debate of dealing with opacity in OT. Besides derivational OT, three parallel OT approaches to deal with opacity in OT are discussed: Sympathy Theory (McCarthy 1999 and 2003), Comparative Markedness (McCarthy 2002) and OT with Candidate Chains (McCarthy 2007). It is argued that Sympathy Theory, for principled reasons, is unable to deal with opaque Latin vowel deletion. The main reason is that the opacity in this case crucially depends on the prosody and not on faithfulness. Comparative Markedness can account for opaque syncope by splitting up the constraints PARSE- $\sigma$ and FT-BIN in new $\left({ }^{N}\right.$ PARSE- $\sigma$ and ${ }^{N}$ FT-BIN $)$ and old $\left({ }^{O}\right.$ PARSE- $\sigma$ and ${ }^{O}$ FT-BIN $)$ constraints. However, the ranking necessary to deal with the cases of opaque deletion leads to incorrect outputs in cases of transparent deletion. Finally, OT with Candidate Chains will be shown to allow for a more restrictive and more principled account of opaque syncope than a serial, level OT approach.

\section{Introduction}

Vowel deletion in Latin has been well-studied throughout the history of Romance linguistics. It has received considerable attention in derivational metrical phonology (Mester 1992, among others) as well as in constraint-based Optimality Theory (OT) (Jacobs 2004). This paper reexamines Latin vowel deletion in its relevance to the actual theoretical debate of how to handle opacity in OT. We will take the analysis of Jacobs (2004) as a starting point. After briefly reviewing it, we will concentrate on some current approaches to deal with opacity in OT: Sympathy Theory (McCarthy 1999 and 2003), Comparative Markedness (McCarthy 2002) and OT with Candidate Chains (McCarthy 2007) examining whether they are capable of providing a fully parallel account. 
This paper is organized as follows. Section 2 reviews Jacobs' analysis, motivates the constraint ranking required for Latin and demonstrates where the prosodic opacity shows up. After that, Section 3 shows why Sympathy Theory, for principled reasons, is unable to deal with similar cases of prosodic opacity. The main reason is that the opacity in this case crucially depends on the prosody and not on faithfulness. Section 4 demonstrates that Comparative Markedness can account for syncope by splitting up the constraint PARSE- $\sigma$ in a new $\left({ }^{\mathrm{N}} \mathrm{PARSE}-\sigma\right)$ and an old ( $\left({ }^{\mathrm{P}} \mathrm{PARSE}-\sigma\right)$ constraint. However, the ranking necessary to deal with the cases of opaque deletion leads to incorrect outputs in cases of transparent deletion. Finally, Section 5 demonstrates that OT with Candidate Chains allows for a more restrictive and more principled account of opaque syncope than a serial, level OT approach.

\section{Latin stress and opaque syncope}

In this section we briefly summarize and review Jacobs' (2004) OT-account of Latin stress and syncope. The OT-constraints used are given in (1).

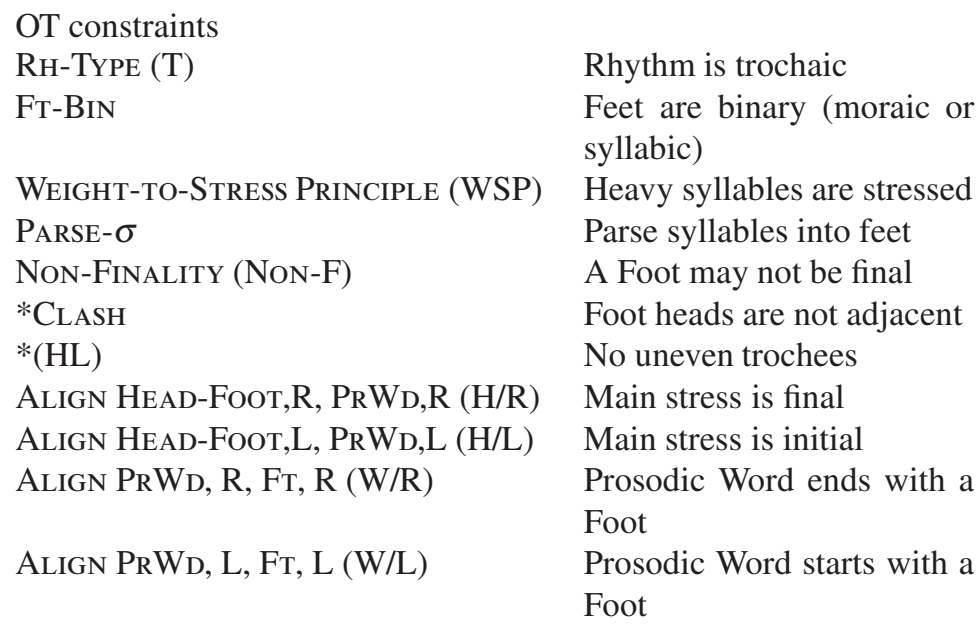

Rhythm is trochaic

Feet are binary (moraic or syllabic)

Heavy syllables are stressed Parse syllables into feet

A Foot may not be final Foot heads are not adjacent No uneven trochees

Main stress is final

Main stress is initial

Prosodic Word ends with a Foot

Prosodic Word starts with a Foot

In Latin, the constraint NoN-F(INALITY) crucially needs to dominate the alignment constraint W/R in order to avoid stress on the final syllable. The constraint $\mathrm{W} / \mathrm{R}$ must dominate $\mathrm{W} / \mathrm{L}$, given that main stress is right-oriented. To get main stress on a prefinal heavy syllable, as in fenéstram 'window' the constraint responsible for quantity-sensitivity WSP must dominate W/L and also PARSE- $\sigma$ as illustrated in (2). Main stress is indicated by boldface, secondary stress by underscore. 
(2)

\begin{tabular}{|l|c|c|c|c|c|}
\hline$/$ LHH/ & NON-F & W/R & WSP & W/L & PARSE \\
\hline fenestram & & & & & \\
\hline$(\mathbf{L ~ H})(\mathrm{H})$ & $* !$ & & $*$ & & \\
\hline$(\mathbf{L ~ H}) \mathrm{H}$ & & $\sigma$ & $* * !$ & & $*$ \\
\hline $\mathbf{L}(\mathbf{H}) \mathrm{H}$ & & $\sigma$ & $*$ & $\sigma$ & $* *$ \\
\hline
\end{tabular}

Latin had secondary stress on the initial syllable, as in civitátem 'city' but not if there was only one syllable before the syllable with main stress, as in mercédem 'salary, profit'. If there were three syllables before main stress, secondary stress also was on the first syllable, unless the first was light and the second heavy LH $\sigma$ (Allen 1973, Jacobs 2003). This means that the constraint CLASH must dominate the constraint responsible for quantity-sensitivity WSP and that both have to dominate W/L and PARSE- $\sigma$ as illustrated in (3), for mercédem 'salary, profit'.

(3)

\begin{tabular}{|c|c|c|c|c|c|c|}
\hline$/ \mathrm{HHH} /$ & NON-F & W/R & ${ }^{*}$ CLASH & WSP & W/L & PARSE \\
\hline mercēdem & & & & & & \\
\hline $\mathrm{H}(\mathbf{H})(\underline{\mathrm{H}})$ & $* !$ & & $*$ & $*$ & $\sigma$ & $*$ \\
\hline$(\underline{\mathrm{H}})(\mathbf{H}) \mathrm{H}$ & & $\sigma$ & $* !$ & $*$ & & $*$ \\
\hline$\underline{\mathrm{H}(\mathbf{H}) \mathrm{H}}$ & & $\sigma$ & & $* *$ & $\sigma$ & $* *$ \\
\hline$(\mathbf{H}) \mathrm{HH}$ & & $\sigma \sigma !$ & & $* *$ & & $* *$ \\
\hline
\end{tabular}

Syncope was operative, but optional, from Early Classical Latin, through Classical Latin and into Late Latin. Some relevant examples of pre- and posttonic syncope are given in (4).

\begin{tabular}{|c|c|c|c|c|c|}
\hline \multicolumn{2}{|c|}{ Post-tonic syncope } & & \multicolumn{3}{|c|}{ Pre-tonic syncope } \\
\hline sŏlĭdus & $>$ soldus & 'solid' & călĕfácere & $>$ calfácere & 'to heat' \\
\hline ārŭdus & $>$ ardus & ‘dry’ & ārĭdórem & $>$ ardórem & 'fire' \\
\hline āmĭnă & $>$ lamna & 'plate' & & & \\
\hline
\end{tabular}

With the constraint $*(\mathrm{HL})$, dominated by W/R and PARSE- $\sigma$ the optimal parse will be one in which the vowel to be deleted is always in the same structural position: the weak part of a foot, as illustrated in tableaux (5)-(8) ${ }^{1}$.

(5)

\begin{tabular}{|l|c|c|c|c|c|c|}
\hline$/ \mathrm{HLH} /$ & NON-F & W/R & WSP & W/L & PARSE & $*(\mathrm{HL})$ \\
\hline ārĭdus & & & & & & \\
\hline$(\mathbf{H L})(\underline{\mathrm{H}})$ & $* !$ & & & & & $*$ \\
\hline$(\mathbf{H}) \mathrm{L}(\underline{\mathrm{H}})$ & $* !$ & & & & $*$ & \\
\hline$(\mathbf{H}) \mathrm{LH}$ & & $\sigma \sigma !$ & $*$ & & $* *$ & \\
\hline \multirow{\mathrm{HL}}{*}{) $\mathrm{H}$} & & $\sigma$ & $*$ & & $*$ & $*$ \\
\hline
\end{tabular}

1. The ranking of $\mathrm{H} / \mathrm{R}$ above $\mathrm{H} / \mathrm{L}$ will guarantee initial secondary stress and main stress on the penultimate/antepenultimate syllable in (7) and (8) 
(6)

\begin{tabular}{|l|c|c|c|c|c|c|}
\hline$/$ LLH/ & NON-F & W/R & WSP & W/L & PARSE & $*(\mathrm{HL})$ \\
\hline sŏlĭdus & & & & & & \\
\hline$(\mathbf{L L})(\underline{\mathrm{H}})$ & $* !$ & & & & & \\
\hline$(\mathbf{L}) \mathrm{L}(\underline{\mathrm{H}})$ & $* !$ & & & & $*$ & \\
\hline$(\mathbf{L}) \mathrm{LH}$ & & $\sigma \sigma !$ & $*$ & & $* *$ & \\
\hline$\square(\mathbf{L L}) \mathrm{H}$ & & $\sigma$ & $*$ & & $*$ & \\
\hline
\end{tabular}

(7)

\begin{tabular}{|l|c|c|c|c|c|c|}
\hline$/ \mathrm{HLHH} /$ & NON-F & W/R & WSP & W/L & PARSE & $*(\mathrm{HL})$ \\
\hline ārūdōrem & & & & & & \\
\hline$(\underline{\mathrm{HL}})(\mathbf{H})(\underline{\mathrm{H}})$ & $* !$ & & & & & $*$ \\
\hline$(\underline{\mathrm{H}}) \mathrm{L}(\mathbf{H})(\underline{\mathrm{H}})$ & $* !$ & & & & $*$ & \\
\hline$(\underline{\mathrm{H}}) \mathrm{L}(\mathbf{H}) \mathrm{H}$ & & $\sigma$ & $*$ & & $* * !$ & \\
\hline$\underline{\mathrm{H}})(\mathbf{H}) \mathrm{H}$ & & $\sigma$ & $*$ & & $*$ & $*$ \\
\hline
\end{tabular}

(8)

\begin{tabular}{|l|c|c|c|c|c|c|}
\hline$/$ LLLLL/ & NON-F & W/R & WSP & W/L & PARSE & $*(\mathrm{HL})$ \\
\hline călĕfacere & & & & & & \\
\hline$(\underline{\mathrm{LL}}) \mathrm{L}(\mathbf{L L})$ & $* !$ & & & & $*$ & \\
\hline$(\underline{\mathrm{L}}) \mathrm{L}(\mathbf{L L}) \mathrm{L}$ & & $\sigma$ & & & $* * !$ & \\
\hline$\underline{\mathrm{LL}}(\mathbf{L L}) \mathrm{L}$ & & $\sigma$ & & & $*$ & \\
\hline
\end{tabular}

Jacobs (2004) analyzes syncope as the relative (optional) ranking of the constraint MAX-V (an underlying vowel should surface) and the constraint $* \mathrm{~V}$ IN $\mathrm{F}(\mathrm{OO}) \mathrm{T}$ (avoid a vowel in the weak position of a foot) and shows that the analysis works in all the contexts in (4), except for the last. That is pre-tonic syncope in words like ârüdorem. This is illustrated in tableau (9) where a deleted vowel is indicated by braces. In order to highlight the pre-main stress part, tableau (9) only provides pre-main stress prosodic structure. Please observe that therefore candidate $(9 \mathrm{c})$ has a violation of $*$ CLASH given that the secondary stressed foot will be adjacent to the main stressed syllable.

(9)

\begin{tabular}{|c|c|c|c|c|c|c|}
\hline$\overline{\text { ărŭ(dō)rem }}$ & *V IN FT & $\overline{M A X-V}$ & *CLASH & $\mathrm{W} / \mathrm{L}$ & PARSE & $*(\mathrm{HL})$ \\
\hline a. $\log (\underline{\mathrm{H}}) \mathrm{L}$ & & & & & $*$ & \\
\hline b. $\quad(\overline{\mathrm{HL}})$ & $* !$ & & & & & $*$ \\
\hline c. $\quad(\underline{\overline{\mathrm{H}}})\langle\mathrm{L}\rangle$ & & *! & $*$ & & & \\
\hline d. $\quad \overline{H L}$ & & & & $\sigma ! \sigma$ & ** & \\
\hline $\begin{array}{ll}\text { e. } & \mathrm{H}\langle\mathrm{L}\rangle\end{array}$ & & *! & & $\sigma$ & * & \\
\hline
\end{tabular}

Syncope in theses cases cannot be achieved by ranking PARSE- $\sigma$ higher, it should then be above ${ }^{*} \mathrm{CLASH}$, which would wrongly produce initial stress in $\mathrm{LH} \sigma$ words like fenestram and HH $\sigma$ words like mercedem in (2) and (3) above. Alternatively, ranking the constraints MAX-V and *V IN F(Oo)T below PARSE$\sigma$, still rules out one of the candidates $(9 \mathrm{c})$ or $(9 \mathrm{e})$ with a syncopated vowel, as illustrated in (10). 
(10)

\begin{tabular}{|l|c|c|c|c|c|c|}
\hline ārĭ(dō)rem & $*$ CLASH & W/L & PARSE & $*$ V IN FT & MAX-V & $*(\mathrm{HL})$ \\
\hline a. $\quad(\underline{\mathrm{H}}) \mathrm{L}$ & & & $* !$ & & & \\
\hline b. ${ }^{*}(\underline{\mathrm{HL}})$ & & & & $*$ & & $*$ \\
\hline c. $\quad(\underline{\mathrm{H}})\langle\mathrm{L}\rangle$ & $* !$ & & & & $*$ & \\
\hline d. $\quad \mathrm{HL}$ & & $\sigma ! \sigma$ & $* *$ & & & \\
\hline e. $\quad \mathrm{H}\langle\mathrm{L}\rangle$ & & $\sigma !$ & $*$ & & $*$ & \\
\hline
\end{tabular}

Neither can syncope in ārüdórem cases be achieved by requiring FT-BIN to hold under syllabic analysis, which would effectively rule out (10a) with a monosyllabic foot resulting from syncope. Although this would correctly ac-

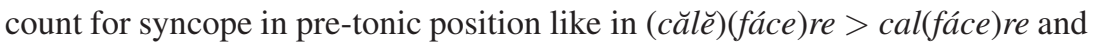
$(\bar{a} r \breve{l})(d o ́) r e m>\operatorname{ar}(d o ́) r e m$, assuming an initial unstressed syllable, it would exclude syncope from taking place in post-tonic position, such as, $($ sŏllu $) d u s>$ $($ sol $) d u s,(\bar{a} r \breve{l}) d u s>($ ar $) d u s$ and $($ lām $\breve{l}) n \breve{a}>($ lam $) n a$, which words also end up with a monosyllabic foot. Replacing the constraint responsible for syncope, *V IN F(OO)T, by one which simply disallows a vowel after a stressed vowel without referring to foot structure, *V STRESS, is not helpful either, as illustrated in (11).

\begin{tabular}{|c|c|c|c|c|c|c|}
\hline ārî(dō)rem & *V STRESS & MAX-V & Clash & $\mathrm{W} / \mathrm{L}$ & PARSE- $\sigma$ & $*(\mathrm{HL})$ \\
\hline a. $\quad(\underline{\mathrm{H}}) \mathrm{L}$ & $* !$ & & & & $*$ & \\
\hline b. $\quad$ (HL) & $* !$ & & & & & * \\
\hline c. $\quad(\underline{\bar{H}})\langle\mathrm{L}\rangle$ & & $* !$ & * & & & \\
\hline $\begin{array}{ll}\text { d. } & \mathrm{H}\langle\mathrm{L}\rangle \\
\end{array}$ & & $* !$ & & $\sigma$ & * & \\
\hline e. $\lg$ H L & & & & $\sigma \sigma$ & $* *$ & \\
\hline
\end{tabular}

Changing the constraint responsible for deletion to *WEAK-V ("no open syllable, short, unstressed, nonfinal" cf. McCarthy, 2007:169), works for the problematic pre-tonic case, as illustrated in (12), but predicts, as illustrated in (13), syncope in solículum 'little sun' to produce incorrect sólclum (13e) instead of correct solíclum (13c).

\begin{tabular}{|c|c|c|c|c|c|c|}
\hline$\overline{\text { ārŭ}(\mathrm{dō}) \mathrm{rem}}$ & *WEAK-V & MAX-V & ClaAsh & $\mathrm{W} / \mathrm{L}$ & PARSE & $*(\mathrm{HL})$ \\
\hline a. $\quad(\mathrm{H}) \mathrm{L}$ & $* !$ & & & & $*$ & \\
\hline b. $\quad(\overline{\mathrm{HL}})$ & $* !$ & & & & & $*$ \\
\hline c. $(\overline{\mathrm{H}})\langle\mathrm{L}\rangle$ & & * & * & & & \\
\hline $\begin{array}{ll}\text { d. } & \mathrm{H}\langle\mathrm{L}\rangle\end{array}$ & $* !$ & * & & $\sigma$ & * & \\
\hline e. $\mathrm{H} \mathrm{L}$ & $* !$ & & & $\sigma \sigma$ & $* *$ & \\
\hline
\end{tabular}




\begin{tabular}{|c|c|c|c|c|c|c|}
\hline soliculum & FT-BIN & *WEAK-V & MAX-V & Clash & $\mathrm{W} / \mathrm{L}$ & PARSE \\
\hline $\begin{array}{ll}\text { a. } & (\mathrm{H})(\mathbf{L L}) \mathrm{H}\end{array}$ & & $* !$ & & $*$ & & \\
\hline b. $\quad(\overline{\overline{\mathrm{H}}})(\mathbf{L})\langle\mathrm{L}\rangle \mathrm{H}$ & *! & & * & * & & * \\
\hline 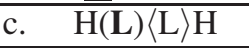 & *! & & $*$ & & $\sigma$ & $* *$ \\
\hline $\begin{array}{ll}\text { d. } & (\mathbf{H}) \mathrm{L}\langle\mathrm{L}\rangle \mathrm{H}\end{array}$ & & $* !$ & * & & & $* *$ \\
\hline e. $(\mathbf{H})\langle\mathrm{LL}\rangle \mathrm{H}$ & & & $* *$ & & & * \\
\hline f $\quad \mathrm{H}(\mathbf{L L}) \mathrm{H}$ & & *! & & & $\sigma$ & ** \\
\hline $\begin{array}{ll}\mathrm{g} & (\mathbf{H L})\langle\mathrm{L}\rangle \mathrm{H}\end{array}$ & & $* !$ & * & & & * \\
\hline
\end{tabular}

It should be noticed that FT-BIN cannot be ranked below *WEAK-V and MAX-V, as this would wrongly lead to stress shift (árúdus $>$ *arídus) instead of syncope (árüdus > ardus) in post tonic syncope, as illustrated in (14).

\begin{tabular}{|l|c|c|c|c|c|c|}
\hline arrĭdus & $*$ WEAK-V & MAX-V & FT-BIN & W/L & PARSE & $*(\mathrm{HL})$ \\
\hline a. (H)L & $* !$ & & & & $*$ & \\
\hline b. (HL) & $* !$ & & & & & $*$ \\
\hline c. $\quad(\mathbf{H})\langle\mathrm{L}\rangle$ & & $* !$ & & & & \\
\hline d. $\mathrm{H}(\mathbf{L})$ & & & $*$ & $\sigma$ & $*$ & \\
\hline
\end{tabular}

Syncope in so(lícu)lum > so(lí)clum clearly shows that syncope leads to prosodic opacity. That is, the actual output of syncope renders the prosodic generalizations of the language opaque, which is clearly visible when one compares sōlltas 'loneliness' with sōliclum. Both words have the same prosodic shape (initial heavy and prefinal light syllable), yet are stressed differently (see Bullock 2000 and Jacobs 2004 and 2006 for a more detailed account showing that the prefinal syllable in these cases indeed remained a light and open syllable). Jacobs (2004) concludes that opaque Latin syncope requires a derivational OT approach and presents an analysis in which prosodic structure results from a first level and deletion from a second level.

In this section, we have briefly reviewed Jacobs (2004). We have motivated the constraint ranking required for Latin and shown where the prosodic opacity shows up. In the next section, we show why Sympathy Theory, for principled reasons, is unable to deal with similar cases of prosodic opacity.

\section{Sympathy and opaque Latin syncope}

There are two versions of Sympathy theory (cf. McCarthy 1999 and McCarthy 2003). What both versions have in common is that a faithfulness constraint (the selector, marked selects a sympathetic base (marked to which output candidates are compared. The essential difference between the two versions is the way in which that comparison is done: by means of a specific sympathy constraint (McCarthy 1999) or, more restrictively, in terms of cumulativity 
(McCarthy 2003). The following example based on Rubach (2000 and 2003) serves to briefly illustrate how Sympathy theory works.

Slovak has a diminutive suffix /æ/ which triggers the palatalization of a preceding stem-final coronal, as in páňa /pan+æ/ > /pañæ/ 'master (diminutive)'. The suffix does not trigger palatalization of preceding stem-final labial consonants, as in holúbä /holub+æ/ 'pigeon (diminutive)'. A further process of æ-backing backs underlying /æ/ to [a] after nonlabials, by which /pañæ/ becomes surface [paña]. In traditional rule terminology, this is an example of a counter-bleeding rule order: the palatalization rule is applied before the rule of æ-backing. Were the order reversed, the æ-backing rule would bleed the palatalization rule.

Tableau (15), where $æ$-backing and palatalization are rendered as respectively *Weak-æ and Palat(alization), shows that without Sympathy (or without a derivational OT (cf. Rubach 2000)) the wrong output candidate results.

\begin{tabular}{|c|c|c|c|c|}
\hline /pan+æ/ & *WEAK-æ & ID [-BACK] & PALAT & ID [ANTERIOR] \\
\hline panæ & $* !$ & & $*$ & \\
\hline pañæ & $* !$ & & & $*$ \\
\hline pana & & $*$ & & \\
\hline paña & & $*$ & & $* !$ \\
\hline
\end{tabular}

A Sympathy analysis runs as follows. If the selector is the constraint IDENT [-BACK], the sympathetic base will be the output candidate (16b) [pañæ], given that (16b) is more harmonic than (16a). The constraint ${ }^{8}$ Cumul evaluates each candidate for whether it accumulates all of the sympathetic candidate's faithfulness violations. As illustrated in (16), this identifies the correct output candidate (16d) as optimal, given that (16a) and (16c) do not accumulate the sympathetic base's faithfulness violation of IDENT [ANTERIOR].

\begin{tabular}{|c|c|c|c|c|c|}
\hline /pan+æ/ & *WEAK æ & CUMUL & ID [BACK] & PALAT & ID [ANTERIOR] \\
\hline panæ & $* !$ & * & & $*$ & \\
\hline b. & *! & & & & * \\
\hline c. pana & & $* !$ & $*$ & & \\
\hline d. paña & & & $*$ & & * \\
\hline
\end{tabular}

Let us next return to opaque Latin syncope in ārŭdórem cases. In (17), we have repeated tableau (9) from above. 


\begin{tabular}{|c|c|c|c|c|c|c|}
\hline$\overline{\text { ārĭ(dō)rem }}$ & $* \mathrm{~V}$ IN FT & MAX-V & *CLASH & $\mathrm{W} / \mathrm{L}$ & PARSE & $*(\mathrm{HL})$ \\
\hline a. $\quad(\underline{H}) \mathrm{L}$ & & & & & $*$ & \\
\hline b. $\quad(\overline{\bar{H}} \mathrm{~L})$ & $* !$ & & & & & $*$ \\
\hline c. $\quad(\underline{\mathrm{H}})\langle\mathrm{L}\rangle$ & & $* !$ & * & & & \\
\hline $\begin{array}{ll}\text { d. } & \text { HL }\end{array}$ & & & & $\sigma ! \sigma$ & $* *$ & \\
\hline $\begin{array}{ll}\text { e. } & \mathrm{H}\langle\mathrm{L}\rangle\end{array}$ & & *! & & $\sigma$ & * & \\
\hline
\end{tabular}

In (17), there is only one faithfulness constraint: MAX-V. This means that only this constraint can function as the selector. There are three potential sympathetic candidates: candidates a, b and $\mathrm{d}$. Candidate a harmonically bounds candidates $b$ and $d$ and is by definition the most harmonic candidate and will therefore be the sympathetic candidate or sympathetic base. Candidate a, however, is the wrong optimal candidate. For Sympathy theory to work, the wrong optimal candidate should violate a sympathetic constraint or should not accumulate all the faithfulness violations of the sympathetic base in order to be ruled out. Given that there is only one faithfulness constraint and given that the wrong optimal candidate (17a) is within the set of potential sympathetic candidates, it cannot by definition be ruled out by cumulativity (or a sympathetic constraint). Thus, Sympathy theory cannot for principled reasons account for this case of opacity, precisely because the opacity depends on prosody and not on faithfulness. In the next section, we show why Comparative Markedness is unable to deal with opaque Latin vowel deletion.

\section{Comparative Markedness and opaque Latin syncope}

Comparative Markedness is not exclusively set up to deal with opacity. McCarthy (2003) shows how it can account for a number of phenomena, among which are derived environment effects, coalescence paradoxes and counterfeeding opacity. The basic idea is straightforward. Markedness constraints normally evaluate candidates without looking at other candidates. Comparative Markedness (and in this sense, it bears a close resemblance with sympathy theory) allows markedness constraints to inspect candidates by comparing them with another candidate: the most faithful, or fully faithful, candidate (FFC). Two situations can arise: the candidate that is evaluated contains a markedness violation that is also present in the FFC ('old' markedness) or one that is not present in the FFC ('new' markedness). This means that every markedness constraint is split up in ${ }^{\mathrm{N}(\mathrm{ew})}$ MARKEDNESS and ${ }^{\mathrm{O}(\mathrm{ld})}$ MARKEDNESS.

In (17) above, there are three faithful candidates $a, b$ and $d$. Which of these faithful candidates is the FFC? The answer is not obvious. The markedness constraints are comparative, which means that they cannot be evaluated without already knowing what the FFC is. McCarthy (2003) proposes that if more 
than one faithful candidate is available, each of the faithful candidates must be assumed to be the FFC itself. The true FFC will then emerge as the most harmonic among the potential FFC's. In tableau (18), this is illustrated. All old and new markedness constraints are ranked contiguously, except ${ }^{\mathrm{O}}$ PARSE.

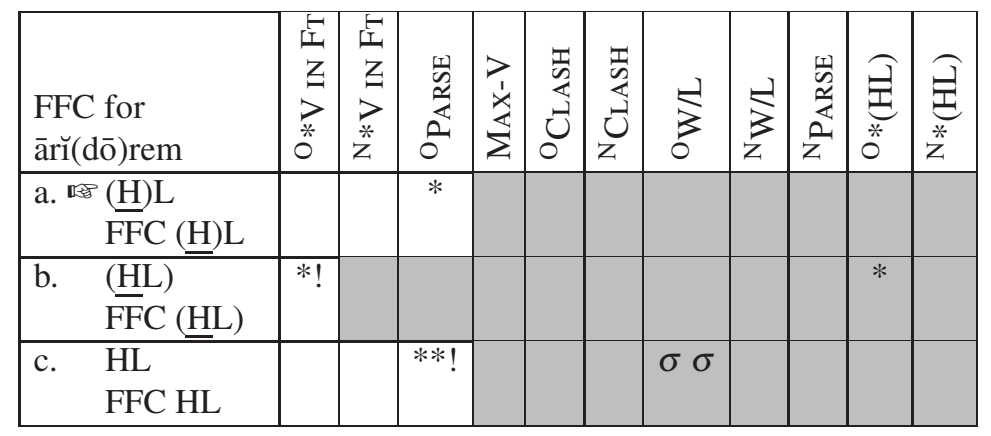

The FFC that emerges as the true FFC in (18) is output candidate a: $(\bar{a}) r \breve{l}(d \bar{o})$ rem, which candidate will then function as the FFC in the evaluation of the full candidate set in (19).

\begin{tabular}{|c|c|c|c|c|c|c|c|c|c|c|c|}
\hline $\begin{array}{l}\bar{a} r \breve{1}(\mathrm{do}) \mathrm{rem} \\
\text { FCC } \\
(\underline{\mathrm{H}}) \mathrm{L}\end{array}$ & $\begin{array}{l}\text { 占 } \\
z \\
z \\
z \\
* \\
0\end{array}$ & \begin{tabular}{|c|}
$\underline{E}$ \\
z \\
$z$ \\
$z$ \\
$z$ \\
$z$
\end{tabular} & 劉 & $\begin{array}{l}>1 \\
\dot{x} \\
\dot{x} \\
\Sigma\end{array}$ & 壱 & 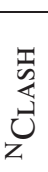 & $\stackrel{2}{3}$ & $\underset{z}{\stackrel{z}{z}}$ & 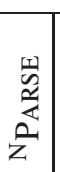 & $\overbrace{0}^{\text {至 }}$ & 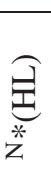 \\
\hline a. $\quad(\underline{H}) \mathrm{L}$ & & & $* !$ & & & & & & & & \\
\hline b. $\quad \overline{\overline{H L}}$ & & $* !$ & & & & & & & & & $*$ \\
\hline c. $\quad(\overline{\mathrm{H}})\langle\mathrm{L}\rangle$ & & & & $*$ & & $* !$ & & & & & \\
\hline d. $\quad \overline{\mathrm{HL}}$ & & & $* !$ & & & & & $\sigma \sigma$ & * & & \\
\hline e. $\mathrm{H}\langle\mathrm{L}\rangle$ & & & & $*$ & & & & $\sigma$ & $*$ & & \\
\hline
\end{tabular}

The ranking in (19) (all old and new markedness constraints ranked contiguously, except ${ }^{\mathrm{O}}$ PARSE placed below the syncope constraint $\mathrm{O} * \mathrm{~V}$ IN FT and ${ }^{\mathrm{N}} * \mathrm{~V}$ IN FT) straightforwardly handles the thus far problematic syncope in ärúdorem $>$ ardórem. It is important to observe, however, that, as mentioned above, there are in principle three faithful candidates in (17). Candidate a harmonically bounds candidate $\mathrm{c}$, which means that candidate $\mathrm{c}$ can never be the FFC. Candidate $\mathrm{b}$, on the other hand, could become the FFC, the result, however, would be incorrect ārüdōrem without vowel deletion, as illustrated in (20) and (21). In (20), again as in (18), the old and new markedness constraints are ranked contiguously, except for ${ }^{O}$ PARSE, which is now ranked topmost, above the syncope constraint $\mathrm{O} * \mathrm{~V}$ IN FT and ${ }^{\mathrm{N}} * \mathrm{~V}$ IN FT. 
(20)

\begin{tabular}{|c|c|c|c|c|c|c|c|c|c|c|c|}
\hline $\begin{array}{l}\text { FFC for } \\
\text { ārî(dō)rem }\end{array}$ & 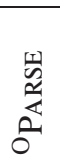 & 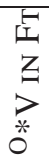 & $\begin{array}{l}\tilde{L} \\
z \\
z \\
z \\
z \\
z\end{array}$ & 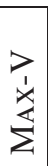 & 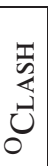 & 己 & $\sum_{0}^{1}$ & $\frac{1}{z}$ & 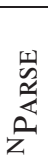 & $\underset{\overbrace{}^{*}}{\stackrel{\ominus}{\Xi}}$ & $\underset{z}{\stackrel{\Xi}{\Xi}}$ \\
\hline $\begin{array}{ll}\text { a. } & \underline{(\mathrm{H}) \mathrm{L}} \\
& \mathrm{FFC}(\underline{\mathrm{H}}) \mathrm{L}\end{array}$ & $* !$ & & & & & & & & & & \\
\hline b. $\frac{(\mathrm{HL})}{\mathrm{FFC}}(\mathrm{HL})$ & & $*$ & & & & & & & & $*$ & \\
\hline $\begin{array}{ll}\text { c. } & \text { HL } \\
& \text { FFC HL }\end{array}$ & $* ! *$ & & & & & & $\sigma \sigma$ & & & & \\
\hline
\end{tabular}

The FFC that now emerges as the true FFC in (20) is output candidate b: $(\bar{a} r \breve{l})(d \bar{o})$ rem. As the evaluation of the full candidate set in (21) shows, no syncope is produced.

\begin{tabular}{|c|c|c|c|c|c|c|c|c|c|c|c|}
\hline $\begin{array}{l}\bar{a} r \breve{r}(\mathrm{dō}) \mathrm{rem} \\
\text { FFC } \\
(\underline{\mathrm{HL}})\end{array}$ & 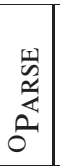 & 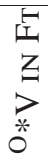 & $\begin{array}{l}\vec{t} \\
z \\
z \\
z \\
z \\
z\end{array}$ & $\underset{⿱ 亠 䒑}{\frac{1}{x}}$ & 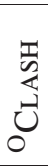 & 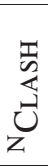 & 羡 & $\frac{1}{z}$ & 点 & $\underset{0}{\stackrel{\ominus}{\Xi}}$ & 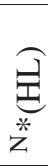 \\
\hline a. $(\underline{\mathrm{H}}) \mathrm{L}$ & & & & & & & & & $*$ & & \\
\hline b. $\quad$ (HL) & & & $* !$ & & & & & & & $*$ & \\
\hline c. $\quad(\underline{\mathrm{H}})\langle\mathrm{L}\rangle$ & & & & $* !$ & & $*$ & & & & & \\
\hline d. $\quad \overline{\mathrm{HL}}$ & & & & & & & & $\sigma ! \sigma$ & $* *$ & & \\
\hline $\begin{array}{ll}\text { e. } & \mathrm{H}\langle\mathrm{L}\rangle \\
\end{array}$ & & & & $* !$ & & & & $\sigma$ & $*$ & & \\
\hline
\end{tabular}

Looking back at (17) it is clear that the only way to rule out the first wrongly optimal candidate is making its sole violation, the violation of PARSE, a violation of OARsE, which, as shown above, is only possible if candidate a is made the FFC, which means ${ }^{O}$ PARSE ranked above MAX-V and below the syn-

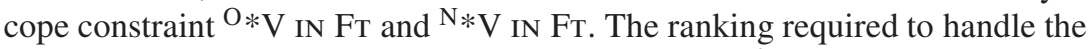
thus far problematic syncope in ārŭdórem $>$ ardórem $^{2}$ also straightforwardly accounts for the other transparent vowel deletion cases, as illustrated for posttonic syncope árüdus > ardus in (22-23).

2. The issue to what extent the language learner is able to make a principled choice for either (18) or (20) will not be addressed here. 
(22)

\begin{tabular}{|c|c|c|c|c|c|c|c|c|c|c|c|}
\hline $\begin{array}{l}\text { FFC for for } \\
\text { ârĭdus }\end{array}$ & 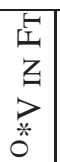 & $\begin{array}{l}\vec{E} \\
\underline{I} \\
z \\
z \\
z \\
z\end{array}$ & 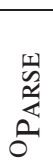 & $\begin{array}{l}z_{1} \\
\dot{x} \\
\dot{x} \\
\Sigma\end{array}$ & 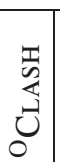 & 䒺 & $b_{0}^{5}$ & $\frac{1}{3}$ & $\begin{array}{c}\frac{1}{2} \\
\frac{2}{2} \\
\frac{a}{2} \\
z\end{array}$ & $\underset{\stackrel{\theta}{\Theta}}{\stackrel{\theta}{*}}$ & 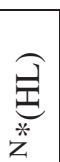 \\
\hline $\begin{aligned} \text { a. } & (\mathbf{H}) \mathrm{LH} \\
& \text { FFC }(\mathbf{H}) \mathrm{LH}\end{aligned}$ & & & ** & & & & & & & & \\
\hline $\begin{array}{ll}\text { b. } & \text { (HL)H } \\
& \text { FFC (HL)H }\end{array}$ & *! & & $*$ & & & & & & & $*$ & \\
\hline
\end{tabular}

(23)

\begin{tabular}{|c|c|c|c|c|c|c|c|c|c|c|c|}
\hline $\begin{array}{l}\text { ārĭdus } \\
\text { FCC } \\
\text { (H)LH }\end{array}$ & $\begin{array}{c}\vec{I} \\
z \\
z \\
* \\
0\end{array}$ & $\begin{array}{l}\vec{y} \\
z \\
z \\
z \\
z\end{array}$ & $\begin{array}{l}\frac{1}{2} \\
\frac{2}{4} \\
\frac{2}{2} \\
0\end{array}$ & 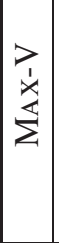 & 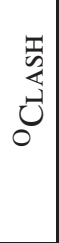 & 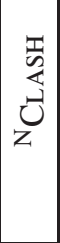 & $\frac{1}{3}$ & $\frac{1}{3}$ & 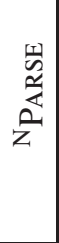 & $\underset{\text { 官 }}{\stackrel{\theta}{*}}$ & 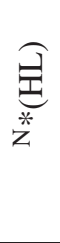 \\
\hline a. $\quad(\mathbf{H}) \mathrm{LH}$ & & & $* * !$ & & & & & & & & \\
\hline $\begin{array}{ll}\text { b. } & \text { (HL)H } \\
\end{array}$ & & $* !$ & * & & & & & & & & $*$ \\
\hline c. $\because(\mathbf{H})\langle\mathrm{L}\rangle \mathrm{H}$ & & & $*$ & $*$ & & & & & & & \\
\hline d. $\quad$ HLH & & & $* * !$ & & & & & $\sigma \sigma$ & * & & \\
\hline e. $\quad \mathrm{H}\langle\mathrm{L}\rangle \mathrm{H}$ & & & $*$ & * & & & & $\sigma !$ & * & & \\
\hline
\end{tabular}

The Comparative Markedness presented here can also correctly account for opaque syncope in solículum $>$ solíclum, if ${ }^{\mathrm{N}}$ FT-BIN is placed below MAX-V, as illustrated in (24) and (25). For reasons of space, the constraints ${ }^{\mathrm{N}} \mathrm{CLASH}$, ${ }^{\mathrm{O}} \mathrm{CLASH}$ and ${ }^{\mathrm{N}} \mathrm{W} / \mathrm{L},{ }^{\mathrm{O}} \mathrm{W} / \mathrm{L}$ have been collapsed in a single column.

(24)

\begin{tabular}{|c|c|c|c|c|c|c|c|c|c|c|c|}
\hline $\begin{array}{l}\text { FCC for } \\
\text { sōlǐcŭlum }\end{array}$ & $\begin{array}{l}z \\
0 \\
\vdots \\
\vdots \\
\vdots \\
0\end{array}$ & $\begin{array}{l}\vec{t} \\
z \\
z \\
z \\
0\end{array}$ & $\begin{array}{c}\overrightarrow{5} \\
z \\
z \\
z \\
z\end{array}$ & $\begin{array}{l}\text { w } \\
\text { a } \\
\text { a }\end{array}$ & 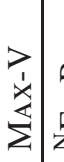 & 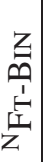 & $\sum_{0}^{\frac{1}{3}}$ & $\frac{z}{z}$ & 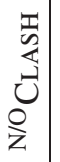 & $\begin{array}{l}\frac{1}{z} \\
\vdots \\
z\end{array}$ & \\
\hline $\begin{array}{ll}\text { a. } & (\mathrm{H})(\mathbf{L L}) \mathrm{H} \\
& \text { FFC }(\mathrm{H})(\mathbf{L L}) \mathrm{H}\end{array}$ & & $* !$ & & $*$ & & & $\sigma$ & & \begin{tabular}{|l|}
$*$ \\
\end{tabular} & & \\
\hline $\begin{array}{ll}\text { b. } & \text { H(LL)H } \\
& \text { FFC H(LL)H } \\
\end{array}$ & & *! & & $* *$ & & & $\sigma$ & & & $\sigma$ & \\
\hline $\begin{aligned} \text { c. } & (\mathbf{H}) \text { LLH } \\
& \text { FFC (H)LLH }\end{aligned}$ & & & & $* * *$ & & & $\sigma \sigma$ & & & & \\
\hline
\end{tabular}


(25)

\begin{tabular}{|c|c|c|c|c|c|c|c|c|c|c|c|}
\hline $\begin{array}{l}\text { sōlǐcŭlum } \\
\text { FCC } \\
\text { (H)LLH }\end{array}$ & 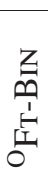 & $\begin{array}{l}\overrightarrow{1} \\
z \\
z \\
0 \\
0\end{array}$ & \begin{tabular}{|c|}
$\underline{1}$ \\
$z$ \\
$z$ \\
$z$ \\
$z$ \\
$z$
\end{tabular} & 劉 & 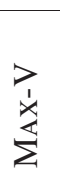 & 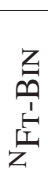 & $\frac{\alpha}{3}$ & $\frac{\alpha}{z}$ & 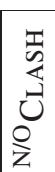 & $\sum_{\substack{z \\
z}}^{1}$ & 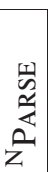 \\
\hline a. $\quad(\mathrm{H})(\mathbf{L L}) \mathrm{H}$ & & & $* !$ & $*$ & & & $\sigma \sigma$ & & * & & \\
\hline b. 吗 $\mathrm{H}(\mathbf{L})\langle\mathrm{L}\rangle \mathrm{H}$ & & & & $*$ & $*$ & $*$ & $\sigma$ & & & $\sigma$ & $*$ \\
\hline $\begin{array}{ll}\text { c. } & (\mathbf{H})\langle\mathrm{LL}\rangle \mathrm{H}\end{array}$ & & & & * & $* * !$ & & $\sigma$ & & & & \\
\hline $\begin{array}{ll}\text { d. } & \mathrm{H}(\mathbf{L L}) \mathrm{H}\end{array}$ & & & $* !$ & * & & & $\sigma$ & & & $\sigma$ & $*$ \\
\hline $\begin{array}{ll}\text { e. } & (\mathbf{H}) \mathrm{LLH}\end{array}$ & & & & $* ! * *$ & & & $\sigma \sigma \sigma$ & & & & \\
\hline
\end{tabular}

For the analysis thus far, it is crucial for deletion in ārúdórem $>$ ardórem that OPARse dominates MAX-V, if not, (19a) without syncope would wrongly become optimal. For opaque deletion (solículum $>$ solíclum), ${ }^{\mathrm{N}}$ FT-BIN must crucially be below MaX-V, if not, $(25 \mathrm{c}$, * solclum) would wrongly become optimal. The ranking required for opaque deletion has two serious drawbacks. First, it wrongly predicts initial stress in fënestram as illustrated in (26) and (27), where we have included ${ }^{\mathrm{O} / \mathrm{N}} \mathrm{WSP}$ and have omitted, irrelevant for this case, ${ }^{\mathrm{O} / \mathrm{N}}$ CLASH and low-ranked ${ }^{\mathrm{O} / \mathrm{N}} *(\mathrm{HL})$.

(26)

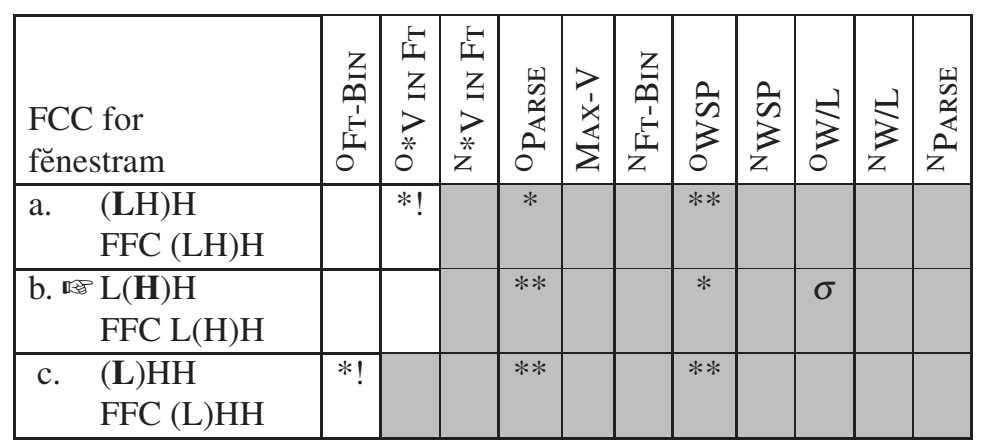

(27)

\begin{tabular}{|c|c|c|c|c|c|c|c|c|c|c|c|}
\hline $\begin{array}{l}\text { fĕnestram } \\
\text { FFC } \\
\mathrm{L}(\mathbf{H}) \mathrm{H}\end{array}$ & $\frac{Z}{n}$ & $\begin{array}{l}\stackrel{t}{ \pm} \\
z \\
z \\
* \\
0\end{array}$ & $\begin{array}{l}\text { tr } \\
z \\
z \\
z \\
z\end{array}$ & 贸 & $\begin{array}{l}>>1 \\
\dot{x} \\
\sum \\
\Sigma\end{array}$ & $\underset{z}{z}$ & $\frac{n}{5}$ & $\frac{n}{z}$ & $\frac{1}{3}$ & $\frac{i}{z}$ & 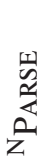 \\
\hline $\begin{array}{ll}\text { a. } & (\mathbf{L H}) \mathrm{H}\end{array}$ & & & $* !$ & $*$ & & & $*$ & $*$ & & & \\
\hline b. $\quad \mathrm{L}(\mathbf{H}) \mathrm{H}$ & & & & $* * !$ & & & * & & $\sigma$ & & \\
\hline c. $(\mathbf{L}) \mathrm{HH}$ & & & & $*$ & & $*$ & $*$ & $*$ & & & $*$ \\
\hline $\begin{array}{ll}\text { d. } & (\mathbf{L})\langle\mathrm{H}\rangle \mathrm{H}\end{array}$ & & & & $*$ & $* !$ & & $*$ & & & & \\
\hline
\end{tabular}

Ranking the constraint ${ }^{\mathrm{N}} \mathrm{FT}$-BIN back again above MAX-V would produce over-application of syncope and result in incorrect *fénstram (27d) and incorrect *sólclum (25c). The problem can be solved if we make the first initial un-

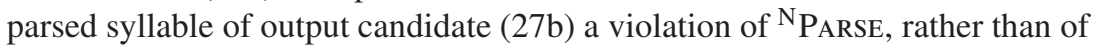


OPARSE. To get this, we need candidate (27a), (fĕnes)tram, as the FFC and not candidate (27b). This can be done by changing the syncope constraint $* \mathrm{~V}$ IN $\mathrm{F}(\mathrm{OO}) \mathrm{T}$ into *L IN F(OO)T (No light unstressed syllable in a foot), as illustrated in (28) and (29). Output candidate (29b), fe(nés)tram, now correctly surfaces as optimal.

(28)

\begin{tabular}{|c|c|c|c|c|c|c|c|c|c|c|c|}
\hline $\begin{array}{l}\text { FFC for } \\
\text { fĕnestram }\end{array}$ & 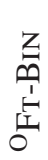 & \begin{tabular}{l}
$\vec{H}$ \\
$\underline{Z}$ \\
$\vec{Z}$ \\
\multirow{2}{*}{}
\end{tabular} & 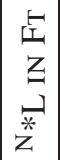 & $\begin{array}{l}\frac{n}{2} \\
\frac{\pi}{4} \\
0\end{array}$ & $\begin{array}{l}> \\
\dot{x} \\
\dot{x} \\
\Sigma\end{array}$ & 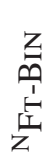 & $\frac{1}{3}$ & $\frac{n}{2}$ & $\sum_{0}^{1}$ & $\sum_{z}^{3}$ & 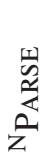 \\
\hline $\begin{aligned} \text { a. } & (\mathbf{L H}) \mathrm{H} \\
& \mathrm{FFC}(\mathbf{L H}) \mathrm{H}\end{aligned}$ & & & & $*$ & & & $* *$ & & & & \\
\hline $\begin{array}{ll}\text { b. } & \mathrm{L}(\mathbf{H}) \mathrm{H} \\
& \text { FFC L(H)H }\end{array}$ & & & & $* * !$ & & & $*$ & & $\sigma$ & & \\
\hline $\begin{array}{ll}\text { c. } & (\mathbf{L}) \mathrm{HH} \\
& \text { FFC }(\mathbf{L}) \mathrm{HH}\end{array}$ & $* !$ & & & $* *$ & & & $* *$ & & & & \\
\hline
\end{tabular}

(29)

\begin{tabular}{|c|c|c|c|c|c|c|c|c|c|c|c|}
\hline $\begin{array}{l}\text { fĕnestram } \\
\text { FFC } \\
(\mathbf{L H}) \mathrm{H}\end{array}$ & 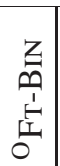 & 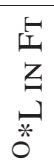 & 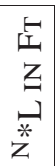 & 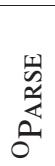 & $\begin{array}{l}> \\
\dot{x} \\
\dot{x} \\
\Sigma\end{array}$ & 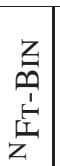 & $\frac{0}{\sqrt[n]{2}}$ & $\begin{array}{l}n \\
z \\
z\end{array}$ & $\sum_{b}^{+1}$ & $\frac{\vec{z}}{z}$ & $\begin{array}{l}\frac{1}{n} \\
\frac{\pi}{2} \\
z\end{array}$ \\
\hline $\begin{array}{ll}\text { a. } & (\mathbf{L H}) \mathrm{H}\end{array}$ & & & & $*$ & & & $* * !$ & & & & \\
\hline b. $\mathrm{L}(\mathbf{H}) \mathrm{H}$ & & & & $*$ & & & $*$ & & & $\sigma$ & $*$ \\
\hline $\begin{array}{ll}\text { c. } & \text { (L)HH }\end{array}$ & & & & $*$ & & $* !$ & $*$ & & & & $*$ \\
\hline $\begin{array}{ll}\text { d. } & (\mathbf{H})\langle\mathrm{L}\rangle \mathrm{H}\end{array}$ & & & & $*$ & $* !$ & & $*$ & & & & \\
\hline
\end{tabular}

The ranking required for opaque deletion ( ${ }^{\mathrm{N}}$ FT-BIN crucially below MAXV) faces a second, more serious, problem. In transparent deletion cases, as in $\bar{a} r \grave{l} d u s>\bar{a} r d u s$, a stress shift is incorrectly predicted: áridus $>$ *arídus. This is shown in (30) and (31). For reasons of space, all contiguous Old and New markedness constraints are presented in single columns. 
(30)

\begin{tabular}{|c|c|c|c|c|c|c|c|c|c|c|c|}
\hline $\begin{array}{l}\text { FFC for } \\
\text { ārĭdus }\end{array}$ & $\begin{array}{l}1 \\
1 \\
z \\
0 \\
z \\
\vdots \\
z\end{array}$ & $\begin{array}{l}z \\
0 \\
\underline{1} \\
\underline{1} \\
0\end{array}$ & $\begin{array}{l}\vec{L} \\
z \\
z \\
\vec{*} \\
\stackrel{0}{z}\end{array}$ & 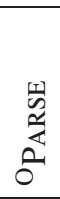 & $\begin{array}{l}\overrightarrow{1} \\
\dot{x} \\
\dot{x} \\
\Sigma\end{array}$ & 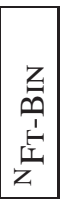 & $\begin{array}{l}n \\
2 \\
3 \\
\vdots \\
z\end{array}$ & $\begin{array}{l}\frac{k}{3} \\
\frac{2}{z}\end{array}$ & 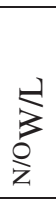 & 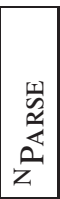 & $\begin{array}{l}\stackrel{\overbrace{}}{\theta} \\
\stackrel{*}{*} \\
\stackrel{*}{z}\end{array}$ \\
\hline $\begin{array}{ll}\text { a. } & \text { (HL)H } \\
& \text { FFC(HL)H }\end{array}$ & & & $* !$ & ** & & & $*$ & $\sigma$ & & & $*$ \\
\hline $\begin{aligned} \text { b. } & (\mathbf{H}) \mathrm{LH} \\
& \operatorname{FFC}(\mathbf{H}) \mathrm{LH}\end{aligned}$ & & & & $* *$ & & & $*$ & $\sigma \sigma$ & & & \\
\hline $\begin{array}{ll}c . & \mathrm{H}(\mathbf{L}) \mathrm{H} \\
& \text { FFC H(L)H }\end{array}$ & & $* !$ & & $* *$ & & & $* *$ & $\sigma$ & $\sigma$ & & \\
\hline $\begin{array}{ll}\text { d. } & (\mathbf{H}) \mathrm{L}(\underline{\mathrm{H}}) \\
& \operatorname{FFC}(\underline{\mathbf{H}}) \mathrm{L}(\underline{\mathrm{H}})\end{array}$ & $* !$ & & & $*$ & & & & & & & \\
\hline
\end{tabular}

(31)

\begin{tabular}{|c|c|c|c|c|c|c|c|c|c|c|c|}
\hline $\begin{array}{l}\bar{a} \text { ř̆dus } \\
\text { FFC } \\
\text { (H)LH }\end{array}$ & $\begin{array}{l}1 \\
1 \\
z \\
0 \\
z \\
0 \\
z\end{array}$ & $\begin{array}{l}z \\
n \\
\stackrel{1}{1} \\
0\end{array}$ & 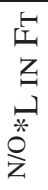 & 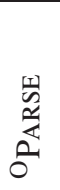 & $\begin{array}{l}> \\
\dot{x} \\
\dot{x} \\
\Sigma\end{array}$ & 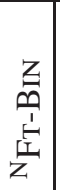 & $\begin{array}{l}0 \\
5 \\
3 \\
0 \\
z\end{array}$ & $\frac{\substack{c \\
z}}{3}$ & $\begin{array}{c}\frac{1}{3} \\
\vdots \\
z\end{array}$ & 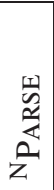 & 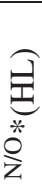 \\
\hline a. $\quad(\mathrm{HL}) \mathrm{H}$ & & & $* !$ & * & & & $*$ & $\sigma$ & & & $*$ \\
\hline b. $\quad(\mathbf{H}) \mathrm{LH}$ & & & & **! & & & * & $\sigma \sigma$ & & & \\
\hline c. $\mathrm{H}(\mathbf{L}) \mathrm{H}$ & & & & $*$ & & $*$ & $* *$ & $\sigma$ & $\sigma$ & $*$ & \\
\hline d. $\quad(\mathbf{H}) \mathrm{L}(\underline{\mathrm{H}})$ & $* !$ & & & $*$ & & & & & & & \\
\hline $\begin{array}{ll}\text { e. } & (\mathbf{H})\langle\mathrm{L}\rangle \mathrm{H}\end{array}$ & & & & $*$ & $* !$ & & $*$ & $\sigma$ & & & \\
\hline
\end{tabular}

There seems no way to prevent this incorrect result. Making $(\bar{a} r \grave{r}) d u s$ the FFC by ranking ${ }^{\mathrm{O}}$ PARSE above ${ }^{\mathrm{N} / 0} * \mathrm{~L}$ IN FT would undo the account for arrüdórem $>$ ardórem, as illustrated in (20/21) above, and would still incorrectly produce optimal (a) rŭdus (31b) instead of syncopated (31e) árdus, as illustrated in (32).

(32)

\begin{tabular}{|c|c|c|c|c|c|c|c|c|c|c|c|}
\hline $\begin{array}{l}\text { ārĭdus } \\
\text { FFC } \\
\text { (HL)H }\end{array}$ & $\begin{array}{l}\text { I } \\
\dot{z} \\
0 \\
\mathbf{z} \\
0 \\
z\end{array}$ & 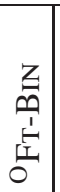 & 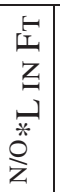 & $\begin{array}{l}\frac{n}{2} \\
\frac{2}{4} \\
0 \\
0\end{array}$ & 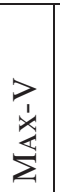 & 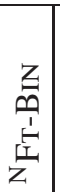 & $\begin{array}{l}n \\
0 \\
\vdots \\
\vdots \\
z \\
z\end{array}$ & $\begin{array}{c}\frac{1}{2} \\
\vdots \\
\vdots \\
z\end{array}$ & $\begin{array}{l}1 \\
\vdots \\
\vdots \\
z \\
z\end{array}$ & 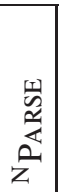 & 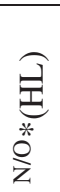 \\
\hline a. $\quad(\mathbf{H L}) \mathrm{H}$ & & & $* !$ & $*$ & & & $*$ & $\sigma$ & & & * \\
\hline b. $(\mathbf{H}) \mathrm{LH}$ & & & & * & & & $*$ & $\sigma \sigma$ & & * & \\
\hline $\begin{array}{ll}\text { c. } & \mathrm{H}(\mathbf{L}) \mathrm{H}\end{array}$ & & & & * & & $* !$ & $* *$ & $\sigma$ & $\sigma$ & * & \\
\hline $\begin{array}{ll}\text { d. } & (\mathbf{H}) \mathrm{L}(\underline{\mathrm{H}})\end{array}$ & $* !$ & & & & & & & & & * & \\
\hline $\begin{array}{ll}\text { e. } & (\mathbf{H})\langle\mathrm{L}\rangle \mathrm{H}\end{array}$ & & & & * & $* !$ & & * & $\sigma$ & & & \\
\hline
\end{tabular}

Ranking ${ }^{\mathrm{N}}$ PARSE and/or ${ }^{\mathrm{N}} \mathrm{W} / \mathrm{L}$ above MAX-V in either (31) or (32) would undo the fĕnestram account in (29). Ranking ${ }^{\mathrm{N}} \mathrm{FT}$-BIN above MaX-V in (31) would bring back the soliculum problem, where it was crucially ranked lower. 
In conclusion, Comparative Markedness can handle transparent deletion, but the ranking that is required for opaque deletion leads to incorrect outputs in cases of transparent deletion, where a stress shift rather than deletion is produced.

The main problem is that the opacity arises because, derivationally speaking, structure building rules (stress) are followed by structure-dependent rules (deletion) that create opacity for the first set of rules. The surface pair sīlutas 'loneliness' and sōlüclus 'sun' clearly show, as mentioned in section 1, that the actual output of syncope renders the prosodic generalizations of the language opaque. Both words have the same prosodic shape (initial heavy and prefinal light syllable), yet are stressed differently. Jacobs (2004) proposes a derivational OT account in which in which prosodic structure results from a first level and deletion from a second level. More specifically, it is assumed that the input to the post-lexical level is the prosodically organized output of the preceding level. Furthermore, a constraint is assumed which requires that stress in the output corresponds to stress in the input.

In the next section, we will first briefly review the derivational OT account and then show that OT with Candidate Chains (OT-CC, McCarthy 2007) permits to account for Latin syncope in a more principled way.

\section{Derivational OT, Candidate Chains and opaque Latin syncope}

A derivational OT analysis of Latin syncope works as follows. First, a lexical constraint ranking assigns prosodic structure. After that a post-lexical ranking takes care of syncope. This is illustrated in (33) and (34) for syncope in ārŭdórem $>$ ardórem.

\begin{tabular}{|c|c|c|c|c|c|c|c|c|c|c|}
\hline $\begin{array}{l}\text { ārǐdōrem } \\
\text { lexical }\end{array}$ & $\begin{array}{l}\text { II } \\
\mathbf{z} \\
0 \\
Z\end{array}$ & $\frac{x}{3}$ & $\begin{array}{l}\overrightarrow{1} \\
\dot{x} \\
\dot{z}\end{array}$ & 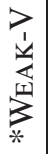 & $\underbrace{\stackrel{5}{厶}}_{*}$ & $\frac{1}{3}$ & $\stackrel{1}{3}$ & 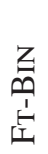 & 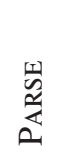 & $\underset{*}{\stackrel{\ominus}{\Xi}}$ \\
\hline a. $(\mathrm{HL})(\mathbf{H}) \mathrm{H}$ & & $\sigma$ & & $*$ & & $*$ & & & $*$ & $*$ \\
\hline b. $\quad(\underline{\mathrm{HL}})(\mathbf{H})(\underline{\mathrm{H}})$ & $* !$ & & & $*$ & & & & & & $*$ \\
\hline c. $\quad(\overline{\mathrm{H}}) \mathrm{L}(\mathbf{H}) \overline{\mathrm{H}}$ & & $\sigma$ & & $*$ & & $*$ & & & $* *$ & \\
\hline d. $\quad(\underline{\mathrm{H}})\langle\mathrm{L}\rangle(\mathbf{H}) \mathrm{H}$ & & $\sigma$ & $* !$ & & $*$ & * & & & $*$ & \\
\hline $\begin{array}{ll}\text { e. } & \mathrm{HL}(\mathbf{H}) \mathrm{H}\end{array}$ & & $\sigma$ & & $*$ & & $* * !$ & $\sigma \sigma$ & & $* * *$ & \\
\hline $\begin{array}{ll}\text { f. } & (\mathbf{H}) \mathrm{LHH}\end{array}$ & & $\sigma \sigma ! \sigma$ & & $*$ & & $* *$ & & & *** & \\
\hline g. $\quad \mathrm{H}\langle\mathrm{L}\rangle(\mathbf{H}) \mathrm{H}$ & & $\sigma$ & $* !$ & & & $* *$ & $\sigma$ & & $* *$ & \\
\hline
\end{tabular}

The optimal output of (33), (àri)(dó)rem, is then input to the post-lexical ranking in (34) and surfaces correctly as (àr)(dó)rem. In order to guarantee that 
lexical stress is preserved post-lexically, a constraint ID(ENT)-STRESS, requiring stress in the output to correspond to stress in the input, is added to the ranking.

\begin{tabular}{|c|c|c|c|c|c|c|c|c|c|c|c|}
\hline $\begin{array}{l}\text { ărĭdōrem } \\
\text { post-lexical } \\
\text { input = } \\
(\underline{\mathrm{HL}})(\mathbf{H}) \mathrm{H}\end{array}$ & 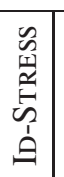 & $\begin{array}{l}\text { I } \\
\vdots \\
\mathbf{z} \\
\mathbf{Z}\end{array}$ & $\frac{x}{3}$ & 章 & 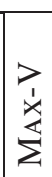 & 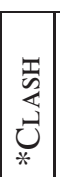 & $\begin{array}{l}\hat{n} \\
3\end{array}$ & $\frac{1}{3}$ & 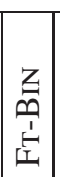 & $\begin{array}{l}\frac{1}{2} \\
\text { 峞 } \\
2\end{array}$ & $\underset{*}{\stackrel{⿴ 囗 十}{*}}$ \\
\hline \begin{tabular}{ll|} 
& $(\mathrm{HL})(\mathbf{H}) \mathrm{H}$
\end{tabular} & & & $\sigma$ & $* !$ & & & $*$ & & & * & * \\
\hline$\overline{(\mathrm{H} L})(\mathbf{H})(\mathrm{H}$ & & $* !$ & & $*$ & & & & & & & * \\
\hline c. $\quad(\overline{\mathrm{H}}) \mathrm{L}(\mathbf{H}) \mathrm{H}$ & & & $\sigma$ & $* !$ & & & $*$ & & & $* *$ & \\
\hline d. $(\overline{\mathrm{H}})\langle\mathrm{L}\rangle(\mathbf{H})$ & & & $\sigma$ & & $*$ & $*$ & $*$ & & & $*$ & \\
\hline $\begin{array}{ll}\text { e. } & \overline{\mathrm{HL}}(\mathbf{H}) \mathrm{H}\end{array}$ & $* !$ & & $\sigma$ & $*$ & & & $* *$ & $\sigma \sigma$ & & **** & \\
\hline (H)LHH & $* !$ & & $\sigma \sigma \sigma$ & $*$ & & & ** & & & **** & \\
\hline $\begin{array}{ll}\text { g. } & \mathrm{H}\langle\mathrm{L}\rangle(\mathbf{H}) \mathrm{H}\end{array}$ & $* !$ & & $\sigma$ & & $*$ & & ** & $\sigma$ & & $* *$ & \\
\hline
\end{tabular}

The same ranking produces opaque syncope as illustrated in (35) and (36) for solículum $>$ solíclum.

(35)

\begin{tabular}{|c|c|c|c|c|c|c|c|c|c|c|}
\hline $\begin{array}{l}\text { sôlǐcŭlum } \\
\text { lexical }\end{array}$ & $\begin{array}{l}\text { I } \\
z \\
0 \\
\text { Z }\end{array}$ & $\frac{2}{3}$ & 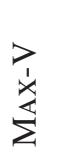 & 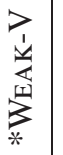 & \begin{tabular}{l}
$\frac{T}{5}$ \\
\multirow{2}{*}{} \\
\multirow{*}{*}{}
\end{tabular} & $\begin{array}{l}\hat{n} \\
\hat{z}\end{array}$ & $\frac{1}{3}$ & 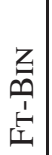 & 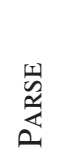 & \\
\hline $\begin{array}{ll}\text { a. } & (\mathrm{H})(\mathbf{L L}) \mathrm{H}\end{array}$ & & $\sigma$ & & $*$ & $* !$ & $*$ & & & * & \\
\hline b. $\quad \overline{\overline{\mathrm{H}(} \mathbf{L L})(\mathrm{H})}$ & $* !$ & & & * & & $*$ & $\sigma$ & & $*$ & \\
\hline $\begin{array}{ll}\text { c. } & \mathrm{H}(\mathbf{L})\langle\mathrm{L}\rangle \overline{\mathrm{H}}\end{array}$ & & $\sigma$ & $* !$ & & & ** & $\sigma$ & $*$ & ** & \\
\hline d. $\quad(\mathbf{H})\langle\mathrm{LL}\rangle \mathrm{H}$ & & $\sigma$ & $*$ ** & & & $*$ & & & $*$ & \\
\hline e. $\mathrm{H}(\mathbf{L L}) \mathrm{H}$ & & $\sigma$ & & * & & ** & $\sigma$ & & ** & \\
\hline $\begin{array}{ll}\text { f. } & (\mathbf{H}) \mathrm{LLH}\end{array}$ & & $\sigma \sigma ! \sigma$ & & ** & & * & & & **** & \\
\hline $\begin{array}{ll}\text { g. } & (\mathbf{H L})\langle\mathrm{L}\rangle \mathrm{H}\end{array}$ & & $\sigma$ & $* !$ & $*$ & & * & & & * & $*$ \\
\hline
\end{tabular}

In (35), the constraints MAX-V and *WEAK-V are crucially ranked above WSP. Had they been ranked lower than WSP, candidate (35g) (*sóliclum with syncope and stress shift) would surface as optimal. The optimal output of (35), so(lícu)lum, is input to post-lexical (36) and surfaces correctly as so(lí)clum. 
(36)

\begin{tabular}{|c|c|c|c|c|c|c|c|c|c|c|c|}
\hline $\begin{array}{l}\text { sōlǐcŭlum } \\
\text { post-lexical } \\
\text { input = } \\
\text { H(LL)H }\end{array}$ & 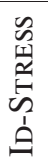 & $\begin{array}{l}\text { I } \\
z \\
0 \\
\text { Z }\end{array}$ & $\frac{x}{3}$ & 紊 & 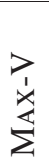 & 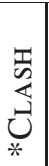 & $\begin{array}{l}\tilde{n} \\
\hat{z}\end{array}$ & $\frac{1}{3}$ & 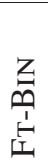 & 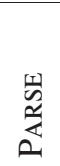 & $\underset{*}{\stackrel{\Theta}{*}}$ \\
\hline a. $\quad(\underline{\mathrm{H}})(\mathbf{L L}) \mathrm{H}$ & & & $\sigma$ & $* !$ & & $*$ & $*$ & & & $*$ & \\
\hline b. $\quad \mathrm{H}(\mathbf{L L})(\underline{\mathrm{H}})$ & & $* !$ & & $*$ & & & $*$ & $\sigma$ & & $*$ & \\
\hline c. 吗 $\mathrm{H}(\mathbf{L})\langle\mathrm{L}\rangle \mathrm{H}$ & & & $\sigma$ & & * & & $* *$ & $\sigma$ & $*$ & $* *$ & \\
\hline $\begin{array}{ll}\text { d. } \quad(\mathbf{H})\langle\mathrm{LL}\rangle \mathrm{H} \\
\end{array}$ & $* !$ & & $\sigma$ & & $* *$ & & * & & & * & \\
\hline e. $\quad \mathrm{H}(\mathbf{L L}) \mathrm{H}$ & & & $\sigma$ & $* !$ & & & $* *$ & $\sigma$ & & $* *$ & \\
\hline $\begin{array}{ll}\text { f. } & \text { (H)LLH }\end{array}$ & $* !$ & & $\sigma \sigma \sigma$ & $* *$ & & & $*$ & & & $* * *$ & \\
\hline $\begin{array}{ll}\text { g. } & (\mathbf{H L})\langle\mathrm{L}\rangle \mathrm{H} \\
\end{array}$ & $* !$ & & $\sigma$ & $*$ & $*$ & & * & & & $*$ & $*$ \\
\hline
\end{tabular}

The derivational OT account correctly describes both Latin transparent and opaque syncope, but it fails to do so in a restrictive enough way. The fact that syncope does never lead to a stress shift is guaranteed by high ranking the constraint ID-STRESS. But, there is no principled way to exclude, for instance, an alternative ranking (FT-BIN high and ID-STRESS low) that would correctly account for syncope in ârŭdórem $>$ ardórem (37), but at the same time would incorrectly produce over-application of opaque syncope and a stress shift (*sólclum), as illustrated in (38).

\begin{tabular}{|c|c|c|c|c|c|c|c|c|c|c|c|}
\hline $\begin{array}{l}\text { ārĭdórem } \\
\text { post-lexical } \\
(\mathrm{HL})(\mathbf{H}) \mathrm{H}\end{array}$ & 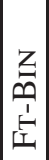 & $\begin{array}{l}1 \\
1 \\
z \\
0 \\
z\end{array}$ & $\frac{q}{3}$ & 立 & $\begin{array}{l}7 \\
1 \\
\dot{x} \\
\sum \\
z\end{array}$ & 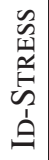 & 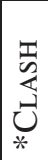 & $\frac{0}{\tilde{3}}$ & $\frac{1}{3}$ & 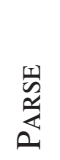 & $\underset{*}{\stackrel{\Xi}{\Xi}}$ \\
\hline a. $(\underline{\mathrm{HL}})(\mathbf{H}) \mathrm{H}$ & & & $\sigma$ & $* !$ & & & & * & & $*$ & $*$ \\
\hline b. $\quad(\underline{\mathrm{HL}})(\mathbf{H})(\underline{\mathrm{H}})$ & & $* !$ & & $*$ & & & & & & & $*$ \\
\hline $\begin{array}{ll}\text { c. } & (\overline{\mathrm{H}}) \mathrm{L}(\mathbf{H}) \mathrm{H}\end{array}$ & & & $\sigma$ & *! & & & & $*$ & & $* *$ & \\
\hline d. $\overline{(\bar{H})}\langle\mathrm{L}\rangle(\mathbf{H}) \mathrm{H}$ & & & $\sigma$ & & $*$ & & $*$ & * & & $*$ & \\
\hline $\begin{array}{ll}\text { e. } & \mathrm{HL}(\mathbf{H}) \mathrm{H} \\
\end{array}$ & & & $\sigma$ & $* !$ & & $*$ & & ** & $\sigma \sigma$ & *** & \\
\hline $\begin{array}{ll}\text { f. } & \text { (H)LHH }\end{array}$ & & & $\sigma \sigma ! \sigma$ & $*$ & & $*$ & & $* *$ & & $* * *$ & \\
\hline $\begin{array}{ll}\text { g. } & \mathrm{H}\langle\mathrm{L}\rangle(\mathbf{H}) \mathrm{H}\end{array}$ & & & $\sigma$ & & $*$ & $* !$ & & $* *$ & $\sigma$ & $* *$ & \\
\hline
\end{tabular}


(38)

\begin{tabular}{|c|c|c|c|c|c|c|c|c|c|c|c|}
\hline $\begin{array}{l}\text { sōlǐcŭlum } \\
\text { post-lexical } \\
\text { input = H(LL)H }\end{array}$ & 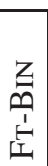 & $\begin{array}{l}I \\
\vdots \\
0 \\
\vdots \\
Z\end{array}$ & $\frac{\alpha}{3}$ & 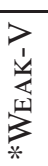 & 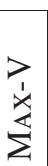 & 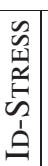 & 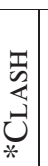 & $\frac{n}{3}$ & $\frac{1}{3}$ & 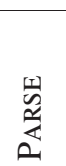 & $\underset{*}{\stackrel{\Xi}{\Xi}}$ \\
\hline $\begin{array}{ll}\text { a. } & (\underline{\mathrm{H}})(\mathbf{L L}) \mathrm{H}\end{array}$ & & & $\sigma$ & $* !$ & & & $*$ & $*$ & & $*$ & \\
\hline b. $\quad \overline{\mathrm{H}(\mathbf{L L})(\mathrm{H})}$ & & $* !$ & & $*$ & & & & $*$ & $\sigma$ & $*$ & \\
\hline c. $\quad \mathrm{H}(\mathbf{L})\langle\mathrm{L}\rangle \overline{\mathrm{H}}$ & $* !$ & & $\sigma$ & & $*$ & & & $* *$ & $\sigma$ & $* *$ & \\
\hline d. 舑 $(\mathbf{H})\langle\mathrm{LL}\rangle \mathrm{H}$ & & & $\sigma$ & & $* *$ & $*$ & & $*$ & & $*$ & \\
\hline $\begin{array}{ll}\text { e. } & \mathrm{H}(\mathbf{L L}) \mathrm{H}\end{array}$ & & & $\sigma$ & *! & & & & $* *$ & $\sigma$ & $* *$ & \\
\hline $\begin{array}{ll}\text { f. } & (\mathbf{H}) \mathrm{LLH}\end{array}$ & & & $\sigma \sigma ! \sigma$ & $* *$ & & $*$ & & $*$ & & $* * *$ & \\
\hline $\begin{array}{ll}\text { g. } & (\mathbf{H L})\langle\mathrm{L}\rangle \mathrm{H}\end{array}$ & & & $\sigma$ & $* !$ & $*$ & * & & $*$ & & $*$ & $*$ \\
\hline
\end{tabular}

To summarize, a serial or derivational OT approach describes the Latin syncope facts, but, without independently motivated restrictions on possible lexical and post-lexical rankings, not in a restrictive enough way. Let us show next that OT with Candidate Chains (OT-CC, McCarthy 2007) permits to account for Latin syncope in a more principled way.

OT-CC offers a new way of dealing with opacity. Both counter-feeding and counter-bleeding are dealt with by the same theory. The basic difference with classic OT is that evaluation does not take into account every possible candidate, but evaluates only well-formed chains connecting a given input to an output. A candidate is a chain of forms connecting input to output. The first member of every candidate chain is a fully faithful parse, violating no faithfulness constraints. A single faithfulness violation in a specific location is a LUM (localized unfaithful mapping). Successive forms in a chain are required to accumulate all of their predecessors LUMs and add only, exactly, one LUM. Moreover, every successive form has to be more harmonic than its predecessor. In order to deal with counter-feeding and counter-bleeding opacity, a new type of constraint is used, PREC constraints, which have the general form PREC $(A, B)$, where A and B are faithfulness constraints and which are violated whenever a B-violating LUM is not preceded by an A-violating LUM in a candidate chain or/and whenever a B-violating LUM is followed by (precedes) an Aviolating LUM in a candidate chain (cf. McCarthy 2007 for a more detailed account).

Important for present purposes is the fact the prosodic opacity created by vowel deletion is neither counter-feeding nor counter-bleeding. This means that no PREC constraints are needed and that the OT-CC account of opaque Latin syncope relies only on the principles of chain theory and on the additional assumption that both stress assignment and stress removal are LUMs (McCarthy 2007: 153) formalized as MAX-PR (no stress removal) and DEP-PR (no stress assignment). 
In order to determine the well-formed candidate chains for underlying /soliculum/, let us repeat in (39) its lexical ranking from (35) above.

\begin{tabular}{|c|c|c|c|c|c|c|c|c|c|c|c|}
\hline $\begin{array}{l}\text { sōlǐcŭlum } \\
\text { lexical }\end{array}$ & $\begin{array}{l}\text { I } \\
\text { ż } \\
\text { z }\end{array}$ & $\frac{x}{3}$ & 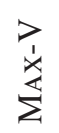 & $\frac{1}{4}$ & 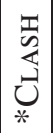 & $\begin{array}{l}2 \\
2 \\
3\end{array}$ & $\frac{3}{3}$ & $\begin{array}{l}z \\
\vdots \\
1 \\
1 \\
1\end{array}$ & 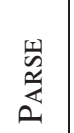 & $\underset{*}{\stackrel{\Theta}{*}}$ & 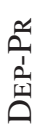 \\
\hline $\begin{array}{ll}\text { a. } & (\mathrm{H})(\mathbf{L L}) \mathrm{H}\end{array}$ & & $\sigma$ & & $*$ & $* !$ & $*$ & & & $*$ & & ** \\
\hline b. $\quad \overline{\mathrm{H}(\mathbf{L L})(\underline{\mathrm{H}})}$ & $* !$ & & & $*$ & & * & $\sigma$ & & * & & ** \\
\hline c. $\quad \mathrm{H}(\mathbf{L})\langle\mathrm{L}\rangle \mathrm{H}$ & & $\sigma$ & $* !$ & & & $* *$ & $\sigma$ & * & $* *$ & & $*$ \\
\hline $\begin{array}{ll}\text { d. } & (\mathbf{H})\langle\mathrm{LL}\rangle \mathrm{H}\end{array}$ & & $\bar{\sigma}$ & $*$ !* & & & * & & & * & & * \\
\hline e. $\mathrm{H}(\mathbf{L L}) \mathrm{H}$ & & $\sigma$ & & * & & ** & $\sigma$ & & ** & & * \\
\hline $\begin{array}{ll}\text { f. } & \text { (H)LLH } \\
\end{array}$ & & $\sigma \sigma ! \sigma$ & & ** & & * & & & **** & & * \\
\hline g. $\quad(\mathrm{HL})\langle\mathrm{L}\rangle \mathrm{H}$ & & $\sigma$ & $* !$ & * & & * & & & * & * & $*$ \\
\hline
\end{tabular}

In (39), we have included DEP-PR (no stress assignment) and assumed that, to get any stress assignment at all, it is located below the other constraints listed in (39). Not all of the seven output candidates in (39) are well-formed candidate chains. Crucially, the ones that display both a stress shift and syncope, candidates $\mathrm{d}$ and $\mathrm{g}$, are among the ill-formed candidate chains, which means that a stress shift resulting from syncope is excluded in principle. If successive forms in a chain are required to accumulate all of their predecessors LUMs and add only, exactly one LUM and if every successive form has to be more harmonic than its predecessor, then only the chains in (40a) are well-formed, but not the ones in (40b). Following McCarthy's notation, the fully faithful initial form is indexed and a LUM is indexed for the locus of violation.

$$
\begin{aligned}
& \text { a. } \mathrm{f}\left\langle\mathrm{s}_{1} \mathrm{O}_{2} \mathrm{l}_{3} \mathrm{i}_{4} \mathrm{c}_{5} \mathrm{u}_{6} \mathrm{l}_{7} \mathrm{u}_{8} \mathrm{~m}_{9}, \text { (só)liculum }\right\rangle \\
& \mathrm{e}\left\langle\left\langle\mathrm{s}_{1} \mathrm{o}_{2} \mathrm{l}_{3} \mathrm{i}_{4} \mathrm{c}_{5} \mathrm{u}_{6} \mathrm{l}_{7} \mathrm{u}_{8} \mathrm{~m}_{9}, \text { so(lícu)lum }\right\rangle\right. \\
& \mathrm{c}\left\langle\mathrm{s}_{1} \mathrm{o}_{2} \mathrm{l}_{3} \mathrm{i}_{4} \mathrm{c}_{5} \mathrm{u}_{6} \mathrm{l}_{7} \mathrm{u}_{8} \mathrm{~m}_{9}, \text { so(lícu)lum, so(lí)clum }\right\rangle \\
& \mathrm{f}=\text { well-formed }\langle\text { DEP-PR@2 }\rangle \text { is the only LUM } \\
& \mathrm{e}=\text { well-formed }\langle\text { DEP-PR@ } 4\rangle \text { is the only LUM } \\
& \mathrm{c}=\text { well-formed }
\end{aligned}
$$

〈DEP-PR@4, MAX-V@6〉 is harmonically improving (*WEAK-V located higher than MAX-V)

b. $\quad \mathrm{a} * *\left\langle\mathrm{~s}_{1} \mathrm{O}_{2} \mathrm{l}_{3} \mathrm{i}_{4} \mathrm{c}_{5} \mathrm{u}_{6} \mathrm{l}_{7} \mathrm{u}_{8} \mathrm{~m}_{9}\right.$, so(lícu)lum, (sò)(lícu)lum $\rangle$

$\mathrm{b} * *\left\langle\mathrm{~s}_{1} \mathrm{O}_{2} \mathrm{l}_{3} \mathrm{i}_{4} \mathrm{c}_{5} \mathrm{u}_{6} \mathrm{l}_{7} \mathrm{u}_{8} \mathrm{~m}_{9}\right.$, so(lícu)lum, so(lícu)(lùm) $\rangle$

$\mathrm{g} * *\left\langle\mathrm{~s}_{1} \mathrm{O}_{2} \mathrm{l}_{3} \mathrm{i}_{4} \mathrm{c}_{5} \mathrm{u}_{6} \mathrm{l}_{7} \mathrm{u}_{8} \mathrm{~m}_{9}\right.$, so(lícu)lum, so(lí)clum, *(sóli)clum $\rangle$

$\mathrm{d} * *\left\langle\mathrm{~s}_{1} \mathrm{O}_{2} \mathrm{l}_{3} \mathrm{i}_{4} \mathrm{c}_{5} \mathrm{u}_{6} \mathrm{l}_{7} \mathrm{u}_{8} \mathrm{~m}_{9}\right.$, so(lícu)lum, so(lí)clum, *(sóli)clum,

(sól)clum $\rangle$

$\mathrm{a}=$ ill-formed

〈DEP-PR@4, DEP-PR@2〉 is not harmonically improving

(*CLASH ranked above DEP-PR) 
$\mathrm{b}=$ ill-formed

〈DEP-PR@4, DEP-Pr@8〉 is not harmonically improving

(Non-F ranked above DeP-PR)

$\mathrm{g}=$ ill-formed $\langle$ DEP-PR@4, MAX-V@6, two LUM's added at * $\rangle$

$\mathrm{d}=$ ill-formed $\langle$ DEP-PR@4, MAX-V@6, two LUM's added at *〉

The last two candidate chains are ill-formed because they contain a successive form that has added two LUM violations (MAX-PR and DEP-PR) in going from so(li)clum to (soli)clum. It should also be observed that a chain 〈soliculum, so(licu)lum, so(li)clum, soliclum, (soli)clum〉 although it avoids the two LUM violations (MAX-PR and DEP-PR) in a successive form, is still ill-formed by not being harmonically improving in going from so(li)clum to soliclum, given that W/R is assumed to be higher ranked than MAX-PR.

Turning back to tableau (39), OT-CC thus singles out the candidates a, b, $\mathrm{d}$ and $\mathrm{g}$ from becoming optimal outputs, given that they constitute ill-formed candidate chains. Either because they contain two LUM violations in one successive form (candidates $\mathrm{d}$ and $\mathrm{g}$ ) or because they are not harmonically improving (candidates a and b). The single reranking of MAX-V and *WEAK-V is thus sufficient to account for opaque syncope, as illustrated in (41), where illformed candidate chains are indicated by a double asterisk and by grey shading. Well-formed competing candidate chains have no shading.

\begin{tabular}{|c|c|c|c|c|c|c|c|c|c|c|c|}
\hline sōlǐcŭlum & $\mid \begin{array}{l}I \\
\vdots \\
z \\
z \\
Z\end{array}$ & $\frac{q}{3}$ & 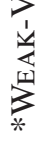 & $\begin{array}{l}> \\
\dot{x} \\
\dot{x} \\
\Sigma\end{array}$ & 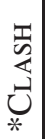 & $\begin{array}{l}\hat{n} \\
\hat{3}\end{array}$ & $\frac{1}{3}$ & $\begin{array}{l}z \\
\underline{n} \\
\underline{1} \\
\underline{1}\end{array}$ & 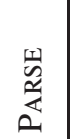 & $\underset{*}{\stackrel{\Xi}{\Xi}}$ & $\begin{array}{l}\frac{1}{2} \\
\stackrel{1}{1} \\
\stackrel{1}{0}\end{array}$ \\
\hline a. $\quad * *(\underline{\mathrm{H}})(\mathbf{L L}) \mathrm{H}$ & & $\sigma$ & * & & $*$ & $*$ & & & $*$ & & $* *$ \\
\hline b. $\quad * * \overline{\mathrm{H}}(\mathbf{L L})(\underline{\mathrm{H}})$ & $*$ & & $*$ & & & * & $\sigma$ & & $*$ & & $* *$ \\
\hline c. $\mathrm{H}(\mathbf{L})\langle\mathrm{L}\rangle \mathrm{H}$ & & $\sigma$ & & * & & ** & $\sigma$ & * & $* *$ & & $*$ \\
\hline d. $\quad * *(\mathbf{H})\langle\mathrm{LL}\rangle \mathrm{H}$ & & $\sigma$ & & $*$ & & $*$ & & & * & & $*$ \\
\hline e. $\quad \mathrm{H}(\mathbf{L L}) \mathrm{H}$ & & $\sigma$ & $* !$ & & & $* *$ & $\sigma$ & & $* *$ & & $*$ \\
\hline $\begin{array}{ll}\text { f. } & (\mathbf{H}) \mathrm{LLH}\end{array}$ & & $\sigma \sigma ! \sigma$ & $* *$ & & & $*$ & & & **** & & $*$ \\
\hline 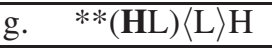 & & $\sigma$ & * & $*$ & & * & & & * & * & $*$ \\
\hline
\end{tabular}

In conclusion, OT-Candidate Chains allows for a straightforward account of opaque syncope, not by using Precedence Constraints, but by chain theory itself. There are simply no well-formed possible chains, that is, no harmonically gradually improving chains, connecting underlying /sōlǐclum/ to less opaque or transparent output competitors, such as, for instance, [sōlı̌clum] or [sōlclum] with initial surface transparent stress. Under the constraint ranking required for Latin with vowel deletion, the only well-formed chain possible is one that links /sōlǐclum/ to the actual opaque output [sōlǐclum]. OT-CC thus offers a full parallel account of opaque Latin syncope and is more restrictive than a serial or 
stratal OT analysis, given that it excludes in principle syncope to lead to stress shift. Obviously, OT-CC does not predict that syncope should always lead to prosodic opacity. A fully transparent Latin-like vowel deletion system is of course possible depending on the relative ranking of FT-BIN and *WEAK-V.

\section{Summary and discussion}

This paper has focused on three recent approaches to deal with opacity in OT: Sympathy Theory (McCarthy 1999 and 2003), Comparative Markedness (McCarthy 2002) and Candidate Chains (McCarthy 2007) and has examined whether they are capable of providing a fully parallel account of Latin prosodic opacity. It has been shown why Sympathy Theory, for principled reasons, is unable to deal with similar cases of prosodic opacity. The main reason is that the opacity in this case crucially depends on the prosody and not on faithfulness. Comparative Markedness can describe transparent deletion, but the ranking required for opaque deletion was shown to lead to incorrect outputs in cases of transparent deletion. The main problem, as we have demonstrated, is that the ranking that is required to handle opaque deletion successfully, wrongly predicts stress shift instead of vowel deletion in cases of transparent deletion. After that, we have briefly compared the level OT approach (cf. Jacobs 2004) with an OT-Candidate Chains account and have demonstrated that the latter allows for a fully parallel and more principled account of account of opaque syncope than a serial OT approach.

Radboud University Nijmegen

\section{References}

Allen, W. Sidney (1973). Accent and Rhythm. Cambridge: Cambridge University Press.

Bullock, Barbara (2001). Double prosody and stress shift in Proto-Romance. Probus 13: 173-192. Jacobs, Haike (2004). Rhythmic vowel deletion in OT: Syncope in Latin. Probus 16: 63-90.

Jacobs, Haike (2006). Proto-Romance stress shift revisited. In New Perspectives on Romance Linguistics, Jean-Pierre Montrueil (ed.), 141-154. Amsterdam: John Benjamins.

McCarthy, John J. (1999). Sympathy and phonological opacity. Phonology 16: 331-399.

McCarthy, John J. (2003). Sympathy, cumulativity, and the Duke-of-York gambit. In The Syllable in Optimality Theory, Caroline Féry and Ruben van de Vijver (eds.), 23-76. Cambridge: Cambridge University Press.

McCarthy, John J. (2003). Comparative markedness. Theoretical Linguistics 29: 1-51.

McCarthy, John J. (2007). Hidden Generalizations. Phonological Opacity in Optimality Theory. London: Equinox.

Mester, R. Armin (1994). The quantitative trochee in Latin. Natural Language and Linguistic Theory 12: 1-61.

Rubach, Jerzy (2000). Glide and glottal stop insertion in Slavic languages. A DOT analysis. Linguistic Inquiry 31: 271-317.

Rubach, Jerzy (2003). Polish palatalization in derivational optimality theory. Lingua 113: 197-237. 